\title{
INFLATION TARGETING, EXCHANGE RATE VOLATILITY AND INTERNATIONAL POLICY COORDINATION
}

\author{
by \\ FERNANDO ALEXANDRE \\ Birkbeck College and University of Minho \\ and \\ JOHN DRIFFILL and FABIO SPAGNOLO* \\ Birkbeck College
}

\begin{abstract}
In a linear rational expectations two-country model, using an aggregate demand, aggregate supply framework, we analyse the effects of the adoption of an inflation-targeting regime on exchange rate volatility and the possible scope for policy coordination. This analysis is conducted using optimized interest rate policy rules within a calibrated model. Rules for interest rates that respond either to exchange rates or to portfolio shocks give improved performance and permit gains from international coordination. Optimized Taylor rules perform relatively well.
\end{abstract}

\section{INTRODUCTION}

Inflation targeting has become part of the new orthodoxy on monetary policy. The ingredients are delegation of monetary policy to an independent central bank, use of short-term interest rates as the instrument of policy, inflation targeting, and floating exchange rates. Individual countries set interest rates independently to meet their own inflation targets; there is no coordination of policies among countries. This appears to have become a successful recipe for macroeconomic management, at least in so far as inflation has been low in most of the developed world from the mid-1990s, there has been growth in some countries, most obviously the USA, and exchange rate fluctuations have been the cause of only moderate and intermittent concerns. International coordination of economic policy is conspicuously almost completely absent from the agenda, both among policymakers and in the scholarly world. ${ }^{1}$

There is an interesting contrast to be drawn between this new

* The authors are extremely grateful to Pedro Bação from Birkbeck College and University of Coimbra for helpful comments. The usual disclaimer applies. Fernando Alexandre also acknowledges financial support from the Subprograma Ciência e Tecnologia do Segundo Quadro Comunitário de Apoio, grant number PRAXIS/BD/19895/99. Support from the ESRC research programme Understanding the Evolving Macroeconomy via research grant L138251003 is gratefully acknowledged.

${ }^{1}$ Coordinated policy actions are sporadic. There was concerted intervention to support the euro in autumn 2000. There has been concern about the effects of the value of the yen on Japanese recovery prospects, but no real action. 
millennial orthodoxy and the one that prevailed around 20 years ago. Then floating exchange rates ruled, but the nominal anchor was to be provided by control of the money supply. Whether because the economic conditions of the times were more agitated, or because control of monetary aggregates was a less good model for policy, exchange rates were highly volatile in the early 1980s. The swings in the value of the major currencies were the cause of great concern, provoked policy intervention, and stimulated much scholarly analysis. The then young CEPR made international economic policy coordination one of the themes of its research programme in international macroeconomics. ${ }^{2}$

The arguments in favour of policy coordination made at that time were based on there being spillovers of the effects of policy between countries under floating exchange rates. Countries responding independently to a common adverse supply shock would be inclined to rely on the exchange rate appreciation induced by a tightening of monetary policy. The overall result was likely to be too much monetary tightening. In other circumstances, in response to other shocks, independent uncoordinated policy actions might be too weak. Coordinated actions by all countries are able in principle to achieve better results for all.

It remains true under a policy that uses setting of short-term interest rates to achieve an inflation target in an environment of floating exchange rates that the spillover effects remain. One of the principal channels of policy transmission in open economies is the exchange rate effect on the consumer price index (CPI) of an interest rate change. Nevertheless there has been relatively little discussion of international coordination of policy to date. This may be because exchange rate volatility is more generally accepted now than it was 20 years ago. In fact exchange rates are currently much less volatile than they were then. It may be because the earlier literature concluded that the gains to be had from coordination were modest.

There has been extensive analysis of inflation targeting in open economies (e.g. Ball, 1999; Sutherland, 2000; Svensson, 2000). Indeed, most of the inflation targeters are small open economies. But there has been little on coordination. The idea of introducing policy responses to asset price bubbles has been mooted by Cecchetti et al. (2000), largely in response to movements in stock prices and real estate, the US stock market, Japan, southeast Asia and so on, with passing observations on exchange rates. In one of few papers on coordinating macroeconomic policy internationally, Obstfeld and Rogoff (2000) examine a fully microfounded model with one-period stickiness in wages and imperfect competition in goods markets. They find little or no scope for coordination to 
be beneficial. In the present paper we examine models with different inflation dynamics that might be induced by overlapping contracts. Monetary policy cooperation is also touched upon by Jensen (2000), while Persson and Tabellini $(1995,2000)$ discuss policy coordination through institutional design.

Against this background, the purpose of this paper is to explore possible effects of coordination of policy among countries that target inflation using interest rates as instruments of policy. While the principal explicit inflation targeters are small open economies-New Zealand, Canada, Sweden, the UK, Australia, Spain - we have modelled a world of just two identical economies.

We employ a linear rational expectations two-country model, using an aggregate demand, aggregate supply framework that combines features of the widely used New Keynesian model of output and inflation with open-economy effects and a set of simple policy rules. We try to answer the following questions. What happens to exchange rate volatility when either or both countries change from a regime where policymakers react directly to deviations of inflation and output from target to using an inflation-forecast rule? Does adding a response to the exchange rate directly or to a portfolio shock reduce exchange rate volatility and improve economic performance? Does the establishment of some sort of coordination between countries result in a better outcome for exchange rate stability and welfare?

An issue that we avoid in this paper is that of time-inconsistency. Throughout the paper, policy rules are evaluated on the basis of the longterm performance of the economy. Effectively it is assumed that the policymakers are able to commit themselves to carrying out any chosen policy rule. Consequently, the issue discussed by Rogoff (1985), that international monetary policy coordination could be counterproductive, does not arise. His results depend on there being a time-inconsistency problem whose bad effects are worsened when countries coordinate on policy. This does not arise in the present paper.

\section{Simple Policy Rules}

We consider five different classes of policy rules. All are interest rate rules, and all are simple rules, in that they make the interest rate dependent on the values taken by a small number of key variables. The exclusive use of interest rate rules for policy rests on the evidence that virtually all industrialized countries' central banks use some short-term (nominal) interest rate as their policy instrument (Walsh, 1998).

Simple rules have been widely discussed among academics and in wider discussions about monetary policy. It has been argued that, particularly when they include forward-looking elements, they may have some 
advantages compared with optimal rules (Batini and Haldane, 1999). First, simple rules may be more robust in the presence of uncertainty about the actual model of the economy (as there always is) than optimal rules, which are typically functions of all the predetermined state variables of the model (Taylor, 1999). Second, it is argued that simple rules, when including forward-looking variables, can perform almost as well as optimal rules in output and inflation stabilization, and still enhance transparency and make the central bank more accountable, resulting, therefore, in higher credibility. Of course, because simple rules do not use all the information available they will not in general be optimal (Black et al., 1997). There is of course a debate as to their descriptive realism. On the one hand, Taylor (1993) has argued that a simple rule - the Taylor rule - is a good description of the Federal Reserve's interest rate policy, and Clarida et al. (1998) have argued that the Bundesbank can be represented as having set German interest rates in response to a few key variables. On the other hand, Ryan and Thompson (2000) remark that no central bank actually uses a simple rule. Rudebusch and Svensson (1999) argue that central banks use all the information available when setting interest rates.

We next briefly describe each of the interest rate rules used in this paper: an optimized Taylor rule, an optimized Taylor rule with an exchange rate term, an optimized forward-looking rule, an optimized forward-looking rule with an exchange rate term and an optimized forward-looking rule with a portfolio shock.

The symbols used in the following equations are defined as follows: $i_{t}$, nominal interest rate; $\pi_{t}$, inflation rate; $y_{t}$, real GDP; $q_{t}$, real exchange rate; $\xi_{t}$, a portfolio shock that affects the exchange rate, described in more detail below in the discussion of our macroeconomic model. All are measured as log deviations from targets except for the nominal interest rate which is in levels. Asterisks denote variables relating to the foreign economy.

\subsection{Optimized Taylor Rule}

The best-known example of a simple rule is the Taylor rule, after Taylor (1993), in which the interest rate reacts to deviations of output and inflation from the target:

$$
\begin{aligned}
& i_{t}=\lambda_{1} \pi_{t}+\lambda_{2} y_{t} \\
& i_{t}^{*}=\rho_{1} \pi_{t}^{*}+\rho_{2} y_{t}^{*}
\end{aligned}
$$

The main arguments for Taylor rules rest on their simplicity, with the transparency and accountability that the central bank gains thereby, and on the fact that they describe actual monetary policy in several 
countries since the mid-1980s (see, for example, Taylor, 1993). Hereafter these rules will be referred to as OTH and OTF for the home and foreign economies, respectively.

\subsection{Optimized Taylor Rule for an Open Economy}

Ball (1999), extending the Svensson (1997) and Ball (1997) model to an open economy, concludes that inflation targets and Taylor rules are suboptimal; different rules are required because monetary policy affects the economy through the exchange rate as well as through interest rate channels. Therefore one might study the case of a policy rule that adds an exchange rate term to the Taylor rule. This is equivalent to the use of a 'monetary conditions index ${ }^{3}$ (an MCI) as an instrument rule, i.e. a weighted sum of the interest rate and the exchange rate:

$$
\begin{aligned}
& i_{t}=\lambda_{1} \pi_{t}+\lambda_{2} y_{t}+\lambda_{3} q_{t} \\
& i_{t}^{*}=\rho_{1} \pi_{t}^{*}+\rho_{2} y_{t}^{*}-\rho_{3} q_{t}
\end{aligned}
$$

Hereafter these will be referred as OTQH and OTQF, respectively.

\subsection{An Inflation-forecast Policy Rule}

A variety of views exist as to the appropriate way of representing a regime of inflation targeting in analyses of this kind. A narrow definition of inflation targeting that has been set out by Svensson (1997) is as a regime in which the interest rate is set so as to achieve the target value for the forecast of the inflation rate at an appropriate horizon. In the same vein, Rudebusch and Svensson (1999) define inflation targeting as 'a framework for policy decisions that involves comparing an inflation forecast to the announced target, thus providing an "inflation-forecast targeting" policy, where the forecast serves as an intermediate target'. They view inflation targeting as a regime in which central bankers can be modelled as setting interest rates using all available information so as to optimize a welfare function that penalizes deviations from the inflation target.

A slightly looser definition of inflation targeting, following Batini and Nelson (2000), McCallum and Nelson (1999a) and others, is as a regime in which the policy instrument reacts to deviations of expected inflation from target, for a given horizon. On this looser definition, a policy would approximate more closely to that under the narrower definition (strict inflation targeting) the greater the strength of the response of the interest rate to the deviation from target. It is argued that such

${ }^{3}$ An MCI emphasizes the fact that monetary policy, in an open economy, has two main channels that affect aggregate demand-interest and exchange rates-and that when interest rates are changed their effects on exchange rates must be considered. 
forecast-based forward-looking rules well approximate the behaviour of inflation-targeting central banks.

Several inflation-targeting countries, including New Zealand, Canada and the UK, base their monetary policy explicitly on inflation forecasts, using them as an intermediate target (see Svensson, 1997; Batini and Haldane, 1999). It is argued that inflation forecasts are likely to be effective intermediate targets. ${ }^{4}$ First, they summarize all the information available - including lags in the transmission of monetary policy-relevant to the target variable. Second, they are controllable by policymakers. The relevance of inflation-forecast rules is supported by the findings of Clarida et al. (1998), to the effect that these rules have summarized the behaviour of a number of central banks since 1979.

In our analysis we will take this wider view of inflation targeting, and represent inflation targeting as the use of a rule that sets the policy instrument (the nominal interest rate) as a function of the deviations of the inflation forecast, for a defined horizon, from the target. The loss function is defined below. The policy rule is

$$
\begin{aligned}
& i_{t}=\gamma E_{t} \pi_{t+j} \\
& i_{t}^{*}=\delta E_{t} \pi_{t+j}^{*}
\end{aligned}
$$

where $i$ is the policy instrument and $\gamma$ is the feedback parameter; $E_{t} \pi_{t+j}$ is the expected value for inflation in period $t+j$, conditional on the information at time $t$; and $j$ defines the targeting horizon with its length determined by the lags in monetary policy and the role given to goals other than inflation. In our analysis, and given the lag structure of our model, we assume that central banks set nominal interest rates in response to deviations of the inflation forecast one period ahead from the target; therefore $j=1$. These rules will be referred to as FWH for the home economy and FWF for the foreign economy hereafter.

There are two important differences between the inflation-forecast rule and a Taylor rule. First, the inflation-forecast rule responds to anticipations of future inflation while the Taylor rule reacts to current or past inflation. (In our application, it is assumed to respond to current inflation.) Second, the inflation-forecast rule does not react directly to the output gap.

In some cases (i.e. for particular assumptions about the structure of the economy) a Taylor rule may provide a means of implementing inflation targeting. Ball (1997) and Svensson (1997), for example, show that an optimal forward-looking rule, representing an inflation-targeting regime,

${ }^{4}$ The requirements of any intermediate target are controllability, predictability and to be a good policy guide. 
may be written as a Taylor rule, but only when current output and current inflation contain all the information necessary to forecast inflation. ${ }^{5}$

\subsection{An Inflation-forecast Rule with an Exchange Rate Term}

In this specification the policymakers react not only to deviations of expected inflation from target but also to deviations of the exchange rate from its long-run equilibrium:

$$
\begin{aligned}
& i_{t}=\gamma_{1} E_{t} \pi_{t+1}+\gamma_{2} q_{t} \\
& i_{t}^{*}=\delta_{1} E_{t} \pi_{t+1}^{*}-\delta_{2} q_{t}
\end{aligned}
$$

The inclusion of an exchange rate term rests on the argument set forth in Cecchetti et al. (2000) that 'central banks can improve macroeconomic performance by reacting systematically to asset prices, over and above their reaction to inflation forecasts and output gaps'. In our open-economy model, because exchange rate fluctuations affect aggregate spending through the export demand channel and affect the CPI through import prices, the reaction of the policy instrument to deviations of the exchange rate from its equilibrium level can then be justified on the grounds that it may help in output and inflation stabilization. Hereafter, these rules are referred as FWQH and FWQF, respectively.

\subsection{An Inflation-forecast Rule with a Response to the Portfolio Shock}

Some authors (Smets, 1997; Cecchetti et al., 2000; Freedman, 2000; for example) argue that interest rates should offset exchange rate movements only when they result from portfolio adjustments. In their study of asset prices and monetary policy, Cecchetti et al. (2000) claim that, because a portfolio shock to the exchange rate can have long lasting effects on output and prices and therefore destabilize the economy, central banks should systematically react to it.

As mentioned above, there is a widespread view in the literature that the benefits of reacting or not reacting to a movement of the exchange rate depend crucially on the cause of that movement. Smets (1997), for example, suggests that the reason why the Bank of Canada used an MCI during the 1990s was because the shocks hitting the exchange rate during that period were due to portfolio adjustments, and that under such circumstances it was beneficial to allow the induced changes in the exchange rate to modify the choice of interest rates. In order to explore this idea in this

${ }^{5}$ Ball (1999), in a model for an open economy, shows that a Taylor rule is not an optimal rule. 
paper, we compare the variance of the system when policymakers react to a portfolio shock with the variance of the system when they do not.

Thus, we consider policy rules where the monetary authorities react to a portfolio shock to the exchange rate (FWSH and FWSF, respectively, hereafter):

$$
\begin{aligned}
& i_{t}=\varphi_{1} E_{t} \pi_{t+1}+\varphi_{2} \xi_{t} \\
& i_{t}^{*}=\varkappa_{1} E_{t} \pi_{t+1}^{*}-\varkappa_{2} \xi_{t}
\end{aligned}
$$

\section{Description of the Model}

The analysis is conducted in an aggregate demand and aggregate supply framework, with elements of the widely used New Keynesian model of output and inflation and including open-economy effects. This framework has emerged in the last decade as broadly consensual and highly useful in the analysis of monetary policy rules (see, for example, Taylor, 1999; Rudebusch, 2000). As argued by Ball (1999), one advantage of this framework is its simplicity and realism in the description of the monetary transmission mechanism. We believe that using a more fully microfounded model would impose very high costs in terms of complexity and would therefore be likely to obscure our results. A simple linear model, such as the one used here, has the additional advantage of making the analysis tractable, allowing the direct computation of the variance of the arguments in the loss function, for example. Our primary objective in using this ad hoc model was to include all the relevant channels in the transmission of monetary policy believed to exist in a two-country model and see how the model works under a set of simple policy rules. Amongst its descriptively realistic features is that it captures the widely verified empirical fact that monetary policy affects output before inflation (see, for example, Walsh, 1998).

The model has the following structure:

$$
\begin{aligned}
& y_{t}=\alpha_{1} E_{t} y_{t+1}-\alpha_{2} r_{t}+\alpha_{3} q_{t-1}+\alpha_{4} y_{t-1}^{*}+\alpha_{5} y_{t-1}+v_{t}+z_{t} \\
& y_{t}^{*}=\alpha_{1} E_{t} y_{t+1}^{*}-\alpha_{2} r_{t}^{*}-\alpha_{3} q_{t-1}+\alpha_{4} y_{t-1}+\alpha_{5} y_{t-1}^{*}+v_{t}^{*}+z_{t} \\
& \pi_{t}=\beta_{1} \pi_{t-1}+\left(1-\beta_{1}\right) E_{t} \pi_{t+1}+\beta_{2} y_{t-1}+\beta_{3}\left(q_{t}-q_{t-1}\right)+\epsilon_{t}+\eta_{t} \\
& \pi_{t}^{*}=\beta_{1} \pi_{t-1}^{*}+\left(1-\beta_{1}\right) E_{t} \pi_{t+1}^{*}+\beta_{2} y_{t-1}^{*}-\beta_{3}\left(q_{t}-q_{t-1}\right)+\epsilon_{t}^{*}+\eta_{t} \\
& r_{t}=r_{t}^{*}+E_{t} q_{t+1}-q_{t}+\xi_{t} \\
& r_{t}=i_{t}-E_{t} \pi_{t+1} \\
& r_{t}^{*}=i_{t}^{*}-E_{t} \pi_{t+1}^{*} \\
& \xi_{t}=\psi \xi_{t-1}+\theta_{t}
\end{aligned}
$$

All the variables in the model are log deviations around the steady state, 
with the exception of nominal interest rates, which are in levels. Variables with an asterisk $(*)$ refer to the foreign economy.

Equations (11) and (12) are dynamic IS curves, of the kind derived by McCallum and Nelson (1999b), with open-economy elements. These authors show that the IS curves can be derived as the linear reduced form of a fully optimizing general equilibrium model. They include a leading term for output that captures the effects of expected income on today's spending. This feature of the IS specification is particularly important in our model, where today's shocks to the foreign economy can be passed through expectations of today's home income. The inclusion of lagged output on the right-hand side of the IS equations, although its theoretical derivation is less clear-cut, is widely agreed to account for adjustment costs that result in some output inertia observable in the data. However, at this stage we set $\alpha_{5}=0$.

Output also depends negatively on the interest rate and positively on a currency depreciation, in the usual way. The exchange rate is defined as the price of foreign currency in terms of domestic money, such that an increase in $q$ represents a real depreciation of the domestic currency. The inclusion of the foreign country income in the IS curve of each country reflects the 'locomotive' effect of one country on the other. Finally, white noise shocks to the IS curve are considered, $v\left(v^{*}\right)$ the country-specific demand shock and $z$ the common shock.

Equations (13) and (14), representing the supply side of the economy, are open-economy Phillips curves. The inclusion of expected and lagged inflation on the right-hand side of the inflation equation, in the New Keynesian form, is strongly supported by several authors (McCallum, 1997; Ball, 1999; Svensson, 1999). The dependence of inflation on its own lagged value reflects inflation persistence, which may result from elements of backward-lookingness in the wage setting process (see Fuhrer and Moore, 1995; Batini and Haldane, 1999). However, there is no agreement on the degree of inflation persistence (see Section 5). Inflation also depends on the output gap with a lag. Additionally, the inflation equations include an open-economy term as in Ball (1999). Inflation depends on the lagged change in the exchange rate because changes in exchange rates are passed directly to inflation via the price of imported goods. ${ }^{6}$ Finally, $\varepsilon\left(\varepsilon^{*}\right)$

${ }^{6}$ Ball (1999) shows that aggregate inflation can be represented as a weighted average of domestic and imported inflation, with weights given by the share of imports and domestic goods in the price index. The inflation rate depends on changes in the exchange rate, which directly influences import prices that enter the definition of the CPI in the following way:

$$
\pi=\Gamma \pi^{\mathrm{d}}+(1-\Gamma) \pi^{\mathrm{m}}
$$

That is, aggregate inflation is an average of domestic inflation $\pi^{\mathrm{d}}$ and import price inflation $\pi^{\mathrm{m}}$, and $1-\Gamma$ is the weight of imported goods in the price index. 
represents the country-specific supply shock and $\eta$ the common shock. These shocks are assumed to be white noise.

Equation (15), the uncovered interest parity condition, is expressed in terms of real exchange rates. This condition includes a term, $\xi$, that can be interpreted as a portfolio shock, assumed to follow an autoregressive process of order 1 , as in equation (18).

Equations (16) and (17) represent the Fisher identity linking the real interest rate, the nominal interest rate and the expected inflation rate. It is required because central banks can only control nominal interest rates $i$, but consumption and investment decisions, and therefore aggregate demand, are based on the ex ante real interest rate.

The policy of the monetary authorities is modelled by interest rate rules (see Section 2). Thus the LM curve is redundant; the demand for money is always accommodated at unchanged interest rates.

\section{The Monetary Transmission Mechanism in the Model}

Because the model's lag structure is fundamental to the analysis to be performed below, the operation of the monetary transmission mechanism is worthy of some words of explanation. An open economy differs from the closed economy case because of the existence of an additional channel: the exchange rate. In a closed economy the real interest rate is the only channel from monetary policy to the real economy and prices. This channel is captured in our simple model in the following way. An increase in the domestic interest rate, for instance, changes the real interest rate, raising the cost of capital, and thereby causing a move in aggregate demand-equation (11). This change in aggregate demand is then transmitted to inflation through the output gap term-equation (13). In this model there is the additional channel of exchange rates, which can work in two different ways: first, indirectly through their effect on exports and consequent impact on the output gap; second, through their direct effect on inflation through their effect on the cost of imported products. The exchange rate also has an important role in the transmission of shocks between countries.

Given the described lag structure, monetary policy affects the country's current output and it affects inflation with one lag, through the traditional real interest rate channel, in accordance with the empirical evidence that monetary policy affects output more rapidly than inflation. And, via the exchange rate channel, it affects current inflation directly and indirectly, through its effect on export demand, with two lags. 


\section{Calibration of the Model}

The parameter values draw upon the work of several authors mentioned below. There is a lack of consensus in the literature concerning the values that the parameters should take.

One of the parameters in this model for which an appropriate value is most difficult to determine is the coefficient of inflation persistence, $\beta_{1}$. The existence of adjustment costs and overlapping price and wage contracts make it realistic to assume some inflation persistence. Rudebusch (2000) refers to several studies (Chadha et al., 1992; Fair, 1993; Brayton et al., 1999; Fuhrer, 1997) and concludes that a plausible range for $\beta_{1}$ would be $[0.4,1]$. In view of the range of plausible values for $\beta_{1}$, and the sensitivity of the results to the value taken by it, we consider throughout our analysis two values, $\beta_{1}=0.4$, representing a relatively forward-looking inflation process, and $\beta_{1}=0.9$, representing more inertial behaviour.

Although there is some empirical evidence supporting the inclusion of lagged output in the IS equation, the uncertainty surrounding an appropriate value and the fact that there is no agreement on its theoretical derivation leads us to set $\alpha_{1}=1$ and $\alpha_{5}=0$, as suggested by McCallum and Nelson (1999b).

Another highly uncertain parameter is the coefficient on the real interest rate, $\alpha_{2}$. Batini and Nelson (2000) note that its value varies widely in studies of policy rules: for quarterly data, it ranges from 0.2 in Estrella and Fuhrer (1998) and McCallum and Nelson (1999a), to 6 in Rotemberg and Woodford (1999). Although such a wide range invites sensitivity analysis, we follow Ball (1999) and set $\alpha_{2}=0.6$.

The open-economy coefficients $\alpha_{3}, \alpha_{4}$ and $\beta_{3}$, and their foreign economy counterparts, depend on the economies' degree of openness. The coefficient $\beta_{3}$ should reflect the weight of imported prices in the CPI. Again, we follow Ball (1999) and we set $\alpha_{3}$ and $\beta_{3}$ equal to 0.2. The effect of lagged output on the other country's demand, given by $\alpha_{4}$, is related to exports. We set it equal to 0.1 .

The parameter on the output gap in the inflation equation is set equal to 0.4, as in Ball (1999). The autoregressive parameter in the portfolio shock is assumed to be equal to 0.8 . The key parameter values of our

TABLE 1

\begin{tabular}{cc}
\multicolumn{2}{c}{ TABLE 1 } \\
\hline Demand equation & Supply equation \\
\hline$\alpha_{1}=1$ & $\beta_{1}=0.9$ \\
$\alpha_{2}=0.6$ & $\beta_{2}=0.4$ \\
$\alpha_{3}=0.2$ & $\beta_{3}=0.2$ \\
$\alpha_{4}=0.1$ & \\
\hline
\end{tabular}


baseline simulations are summarized in Table 1 . We assume that shocks to output, exchange rates and inflation all have a variance of $1 .{ }^{7}$

\section{Solving the Model}

Our multivariate linear rational expectations model is written in the Blanchard-Kahn form (Blanchard and Kahn, 1980) and then solved using the procedure described in Söderlind (1999), applying a Schur decomposition to the coefficient matrix. ${ }^{8}$

The reduced form solution of the model is of the form

$$
X_{t+1}=B X_{t}+C \varepsilon_{t+1}
$$

and the variance-covariance matrix of $X$, denoted by $V$, is given by

$$
\operatorname{vec}(V)=[I-(B \otimes B)]^{-1} \operatorname{vec}(\Omega)
$$

where $\Omega=C V(\varepsilon) C^{\prime} .^{9}$ The variance-covariance matrix of the shocks is the identity matrix in line with the specification above.

\subsection{The Loss Function}

In the search for policy parameters we assume that policymakers seek to minimize the expected value of a loss function that is given by a weighted sum of the unconditional variances of output, inflation and the change in the policy instrument:

$$
E\left(L_{t}\right)=\operatorname{var}\left(\pi_{t}\right)+\omega_{1} \operatorname{var}\left(y_{t}\right)+\omega_{2} \operatorname{var}\left(i_{t}-i_{t-1}\right)
$$

In the baseline simulations, the same weight is given to the variance of output and inflation, with $\omega_{1}=1$, and half this weight is given to the interest rate volatility term, $\omega_{2}=0.5$, following Rudebusch and Svensson (1999) and Rudebusch (2000). We also consider the results of using a different set of utility weights.

The purpose of including the variance of output and changes in interest rates in the objective function is that a considerable body of evidence has grown up to suggest that central banks rarely behave as though inflation is their only objective (Batini and Haldane, 1999; Bernanke et al., 1999). Banks such as the Bank of England, while having a primary objective of inflation stabilization around a target rate, claim that they are not, in the words of Mervyn King, 'inflation nutters'. They also attempt to mitigate fluctuations in output and appear averse to large and

${ }^{7}$ When calculating the optimal policy parameters we varied those variances, and the results appeared fairly robust.

${ }^{8} \mathrm{We}$ ran all the programs in Gauss and used the implementation of the Schur decomposition made available by Söderlind at http://www.hhs.se//personal/psoderlind.

${ }^{9}$ See Hamilton (1994, p. 265). 
frequent movements in interest rates. They seem particularly averse to short-term reversals in interest rate movements. Several authors have argued (see, for example, Mishkin, 1999; Rudebusch and Svensson, 1999) that the central banks' behaviour can be rationalized by the inclusion of the output gap and changes in interest rates along with inflation in the loss function.

The inclusion of an interest rate smoothing term in the loss function reduces the volatility of the policy instrument and, in the view of Mishkin (1999) and others, reflects real concerns of policymakers. Various reasons justify these concerns. First, as noted by Weerapana (2000), in the context of an open economy, the non-inclusion of an interest rate volatility term may generate considerable fluctuations in interest rates as the policymakers use them to eliminate the negative effects of exchange rates. Second, Woodford (1999) provides arguments for the smoothing of interest rates, based on the idea that high interest rate volatility may damage the policymakers' credibility: a succession of small movements of the interest rate in the same direction may enhance public confidence in central bankers. Third, and most importantly, in the view of Mishkin (1999), policymakers are averse to interest rate variability because they are very concerned about financial stability.

It is important to note that in all the analysis in this paper it is assumed that policymakers can adhere to the policy rules that have been chosen. Questions of time-inconsistency do not arise here. The issues by Rogoff (1985) do not apply to our analysis.

\subsection{Non-cooperative and Cooperative Behaviour by Policymakers}

In our analysis, we consider both non-cooperative and cooperative behaviour among policymakers. In the case of non-cooperative behaviour, we look for a Nash equilibrium in policy rules. We assume that each country knows the other's policy rule and optimizes taking it as given. Thus, for example, the domestic policymaker chooses optimal policy parameters (via a grid search), taking as given the policy rule of the foreign country. Knowing (and taking as given) the policy rule of the domestic policymaker, the foreign policymaker then adjusts his own policy rule in order to minimize his loss function. This process is iterated until convergence is attained.

In the cooperative case, we use again a grid search procedure to find the optimal policy parameters. But now it is assumed that the choice is made jointly with the objective of minimizing their joint loss function:

$$
E\left(L_{t}\right)=\operatorname{var}\left(y_{t}\right)+\operatorname{var}\left(y_{t}^{*}\right)+\operatorname{var}\left(\pi_{t}\right)+\operatorname{var}\left(\pi_{t}^{*}\right)+0.5 \operatorname{var}\left(\Delta i_{t}\right)+0.5 \operatorname{var}\left(\Delta i_{t}^{*}\right)
$$


which is a sum of the individual countries' loss functions, reflecting the assumption of symmetry.

\section{Inflation Targeting and Exchange Rate Volatility}

In this section we examine the effects of policymakers' changing from the use of a Taylor rule to the use of inflation targeting, by one or both countries. We make this assessment for policy rules that react to domestic output and inflation and then for policy rules that also include an exchange rate term (see Section 2).

\subsection{Policy Rules without an Exchange Rate Term}

We assume here that policymakers do not react to exchange rate movements when setting interest rates. We compare three scenarios. In the first scenario, both countries use an optimized Taylor rule (OTH/OTF). The policy rules are set out in equations (1) and (2) above. In the second scenario, the home country uses a rule based on an inflation forecast, while the foreign country continues to use an optimized Taylor rule (FWH/ OTF). The rules are as set out in equations (5) and (2) above. And in the third scenario, both countries use policy rules based on inflation forecasts (FWH/FWF), as set out in equations (5) and (6) above. The parameters of the optimal rules are calculated assuming non-cooperative behaviour, employing the grid search procedure described in Section 6, and are presented in Table 2.

It is noticeable that the parameters of the optimized Taylor rule are somewhat different from those found by Taylor (1993). We find that, while the response $\left(\lambda_{1}, \rho_{1}\right)$ to inflation is sensitive to the inflation-persistence parameter $\beta_{1}$, it is of the same order of magnitude (1.5) as found by Taylor. The response to the output gap $\left(\lambda_{2}, \rho_{2}\right)$ at 1.3 here is greater than Taylor's figure of 0.5 , and not sensitive to inflation persistence. These differences reflect differences in the structure of the underlying economic models.

We compute the unconditional variances of the variables of the

TABLE 2

Optimal Parameters in Policy Rules

\begin{tabular}{llllc}
\hline & & OTH and OTF & FWH and OTF & FWH and FWF \\
\hline$\beta_{1}=0.9$ & Home & $\lambda_{1}=2.2 ; \lambda_{2}=1.3$ & $\gamma=2$ & $\gamma=2$ \\
& Foreign & $\rho_{1}=2.2 ; \rho_{2}=1.3$ & $\rho_{1}=2.2 ; \rho_{2}=1.3$ & $\delta=2$ \\
$\beta_{1}=0.4$ & Home & $\lambda_{1}=1.6 ; \lambda_{2}=1.3$ & $\gamma=2.8$ & \\
& Foreign & $\rho_{1}=1.6 ; \rho_{2}=1.3$ & $\rho_{1}=1.7 ; \rho_{2}=1.3$ & $\gamma=2.6$ \\
\hline
\end{tabular}


TABLE 3

Measures of Macroeconomic Performance Under Alternative Policy Rules

\begin{tabular}{|c|c|c|c|c|c|c|}
\hline & \multicolumn{2}{|c|}{$O T H$ and $O T F$} & \multicolumn{2}{|c|}{$F W H$ and $O T F$} & \multicolumn{2}{|c|}{$F W H$ and $F W F$} \\
\hline & $\beta_{1}=0.9$ & $\beta_{1}=0.4$ & $\beta_{1}=0.9$ & $\beta_{1}=0.4$ & $\beta_{1}=0.9$ & $\beta_{1}=0.4$ \\
\hline $\operatorname{var}(i)$ & 5.368 & 4.504 & 5.339 & 4.43 & 5.420 & 4.547 \\
\hline $\operatorname{var}\left(i^{*}\right)$ & 5.368 & 4.504 & 5.388 & 4.448 & 5.420 & 4.547 \\
\hline $\operatorname{var}(y)$ & 3.283 & 1.453 & 3.894 & 1.215 & 3.898 & 1.289 \\
\hline $\operatorname{var}\left(y^{*}\right)$ & 3.283 & 1.453 & 3.321 & 1.561 & 3.898 & 1.289 \\
\hline $\operatorname{var}(\pi)$ & 3.506 & 3.087 & 3.363 & 3.442 & 3.400 & 3.479 \\
\hline $\operatorname{var}\left(\pi^{*}\right)$ & 3.506 & 3.087 & 3.544 & 2.905 & 3.400 & 3.479 \\
\hline $\operatorname{var}(q)$ & 4.831 & 4.997 & 5.584 & 5.462 & 6.682 & 5.948 \\
\hline$L$ & 9.087 & 7.439 & 9.395 & 7.505 & 9.463 & 7.642 \\
\hline$L^{*}$ & 9.087 & 7.439 & 9.138 & 7.343 & 9.463 & 7.642 \\
\hline
\end{tabular}

system in each of the three scenarios set out above, for high and low levels of inflation persistence, and we compute also the value of the loss functions for each case. Table 3 contains the results.

A number of features of these results stand out. Notably, a shift from the use of optimized Taylor rules to inflation-forecast rules by both countries makes them both worse off. This is true for both high and low values of the inflation-persistence parameter, but the deterioration is greater when there is more inflation persistence. If one country alone shifts from the optimized Taylor rule while the other sticks to it, it will be worse off. If these two countries were seen as playing a non-cooperative game in policy rules, then the Taylor rule would be a Nash equilibrium.

The differences between the macroeconomic outcomes are modest. Switching from the Taylor rule to the inflation-forecast rule (by both countries) causes output to become more variable and inflation less variable, when inflation is persistent. But when inflation is less persistent, the opposite is true: output becomes less variable and inflation more so. The variance of the interest rate is barely affected by the choice of policy rule. There is a relatively large increase in the variance of the exchange rate when the Taylor rule is replaced by the inflation-forecast rule, from 4.8 to 6.7 when inflation is very persistent, and from 5.0 to 5.9 when it is less so.

Comparing the properties of the high-inflation-persistence and lowinflation-persistence simulations, the most striking difference is that output is less volatile when inflation is less persistent. When inflation is less persistent, the economy can be stabilized more readily.

\subsection{Policy Rules with an Exchange Rate Term}

What happens when policymakers respond to changes in the exchange rate? We continue to assume that each country acts in its individual best 
interests, and that responses to exchange rate movements are uncoordinated. Again three scenarios are considered, as follows.

When both countries use optimized Taylor rules with an exchange rate term (OTQH/OTQF) the rules are as in equations (3) and (4) above. When only the home country uses an inflation-forecast rule with an exchange rate term while the foreign country uses an optimized Taylor rule with an exchange rate term (FWQH/OTQF) the rules are given by equations (7) and (4). And when both countries use inflation-forecast rules with exchange rate terms (FWQH/FWQF), the rules are (7) and (8).

Again, the optimal policy parameters are computed for the different cases and regimes assuming that policymakers behave non-cooperatively. The coefficients of the optimized rules are presented in Table 4. Comparison of Tables 2 and 4 reveals that when policymakers respond additionally to exchange rate movements their Taylor rules respond less aggressively to inflation and output gaps. The optimized inflation-forecast rule responds less aggressively to the inflation forecast when inflation is persistent, but more aggressively when it is not. The resulting unconditional variances of the variables of the system are set out in Table 5 .

Adding the response to the exchange rate improves overall performance (as measured by the loss function) in every case, as would be expected, since none of these rules is an optimal rule. But the benefits are greater when there is less inflation persistence rather than more, and when the inflation-forecast rule is employed rather than the Taylor rule. While it remains true that both countries are better off when they both use the Taylor rule than when they both use the inflation-forecast rule, the disadvantage of the latter is greatly diminished.

Relative to the scenario in which there is no response to the exchange rate, the variance of the exchange rate is reduced, by between 20 and 30 per cent, roughly speaking.

TABLe 4

Parameter Values of Optimal Policy Rules, Rules Including Response to ExChange Rate

\begin{tabular}{lllll}
\hline & & OTQH vs OTQF & FWQH vs OTQF & FWQH vs FWQF \\
\hline$\beta_{1}=0.9$ & Home & $\lambda_{1}=2 ; \lambda_{2}=1.1 ;$ & $\gamma_{1}=1.9 ; \gamma_{2}=0.3$ & $\gamma_{1}=1.9 ; \gamma_{2}=0.3$ \\
& & $\lambda_{3}=0.2$ & \\
& Foreign & $\rho_{1}=2 ; \rho_{2}=1.1 ;$ & $\rho_{1}=2.1 ; \rho_{2}=1.2 ;$ & $\delta_{1}=1.9 ; \delta_{2}=0.3$ \\
& & $\rho_{3}=0.2$ & \\
$\beta_{1}=0.4$ & Home & $\lambda_{1}=1.3 ; \lambda_{2}=0.8 ;$ & $\gamma_{1}=2.8 ; \gamma_{2}=0.4$ & $\gamma_{1}=2.9 ; \gamma_{2}=0.5$ \\
& & $\lambda_{3}=0.3$ & & \\
& Foreign & $\rho_{1}=1.3 ; \rho_{2}=0.8 ;$ & $\rho_{1}=1.4 ; \rho_{2}=0.8 ;$ & $\delta_{1}=2.9 ; \delta_{2}=0.5$ \\
& & $\rho_{3}=0.3$ & $\rho_{3}=0.3$ & \\
\hline
\end{tabular}


TABLE 5

Performance Measures Under Alternative Policy Combinations with Rules that Respond to the Exchange Rate $(q)$

\begin{tabular}{lcccccccc}
\hline & \multicolumn{2}{c}{ OTQH and OTQF } & & \multicolumn{2}{c}{$F W Q H$ and $O T Q F$} & & \multicolumn{2}{c}{$F W Q H$ and FWQF } \\
\cline { 2 - 3 } \cline { 7 - 8 } \cline { 7 - 8 } & $\beta_{1}=0.9$ & $\beta_{1}=0.4$ & & $\beta_{1}=0.9$ & $\beta_{1}=0.4$ & & $\beta_{1}=0.9$ & $\beta_{1}=0.4$ \\
\hline $\operatorname{var}(i)$ & 5.062 & 3.466 & & 4.874 & 3.886 & & 4.893 & 3.796 \\
$\operatorname{var}\left(i^{*}\right)$ & 5.062 & 3.466 & & 5.097 & 3.497 & & 4.893 & 3.796 \\
$\operatorname{var}(y)$ & 3.300 & 1.649 & & 3.625 & 1.174 & & 3.631 & 1.204 \\
$\operatorname{var}\left(y^{*}\right)$ & 3.300 & 1.649 & & 3.304 & 1.703 & & 3.631 & 1.204 \\
$\operatorname{var}(\pi)$ & 3.605 & 3.142 & & 3.444 & 3.381 & & 3.456 & 3.319 \\
$\operatorname{var}\left(\pi^{*}\right)$ & 3.605 & 3.142 & & 3.581 & 2.945 & & 3.456 & 3.319 \\
$\operatorname{var}(q)$ & 3.967 & 3.747 & & 4.041 & 4.39 & & 4.091 & 4.036 \\
$L$ & 9.009 & 7.084 & & 9.054 & 7.23 & & 9.075 & 7.182 \\
$L^{*}$ & 9.009 & 7.084 & & 9.035 & 6.985 & & 9.075 & 7.182 \\
\hline
\end{tabular}

\section{Portfolio Shocks and Inflation Targeting}

In this section we turn our attention to the relative merits of a policy response to the exchange rate per se and a policy response only to the portfolio shocks that affect the exchange rate. This follows the suggestion of several authors (e.g. Cecchetti et al., 2000; Freedman, 2000) that the policy instrument should only react to exchange rate movements that do not reflect fundamentals. In this section of the paper, we focus on inflation-forecast rules rather than optimized Taylor rules.

We have already seen the effects of reacting directly to the exchange rate in the context of an inflation-forecast rule. It results in lower volatility of the exchange rate and in an improvement in welfare, relative to the situation in which there is only a reaction to deviations of the inflation forecast from target. When inflation is relatively persistent $\left(\beta_{1}=0.9\right)$, there is a decrease in the variances of the interest rate and output, while there is an increase in the variance of inflation. When inflation is less persistent $\left(\beta_{1}=0.4\right)$, reacting to the exchange rate results in a reduction in the variances of all three measures.

What happens when the policymakers respond only to the nonfundamental movements (the portfolio shocks) in the exchange rate? The policy rules that include responses to portfolio shocks are FWSH and FWSF set out in equations (9) and (10) above. The optimal coefficients turn out to be $\varphi_{1}=\varkappa_{1}=1.73$ and $\varphi_{2}=\varkappa_{2}=0.35$ in the scenario with high inflation persistence $\left(\beta_{1}=0.9\right)$, and $\varphi_{1}=x_{1}=2.3$ and $\varphi_{2}=x_{2}=0.5$ in the low-inflation-persistence scenario $\left(\beta_{1}=0.4\right)$. We note that when they react to the portfolio shock rather than to the exchange rate, policymakers' responses to expected future inflation are less aggressive (the coefficient is 1.73 rather than 1.9 , and 2.3 rather than 2.9 ).

The performance of the economy under these rules is set out in 
TABLE 6

Performance Measures for Inflation-forecast Policy Rules

\begin{tabular}{|c|c|c|c|c|c|c|}
\hline & \multicolumn{2}{|c|}{$F W$} & \multicolumn{2}{|c|}{$F W Q$} & \multicolumn{2}{|c|}{$F W S$} \\
\hline & $\beta_{1}=0.9$ & $\beta_{1}=0.4$ & $\beta_{1}=0.9$ & $\beta_{1}=0.4$ & $\beta_{1}=0.9$ & $\beta_{1}=0.4$ \\
\hline \multicolumn{7}{|c|}{ (a) Non-cooperative policies } \\
\hline $\operatorname{var}(i)=\operatorname{var}\left(i^{*}\right)$ & 5.420 & 4.547 & 4.893 & 3.796 & 4.679 & 3.717 \\
\hline $\operatorname{var}(y)=\operatorname{var}\left(y^{*}\right)$ & 3.898 & 1.289 & 3.631 & 1.204 & 3.673 & 1.276 \\
\hline $\operatorname{var}(\pi)=\operatorname{var}\left(\pi^{*}\right)$ & 3.400 & 3.479 & 3.456 & 3.319 & 3.393 & 3.481 \\
\hline $\operatorname{var}(q)$ & 6.682 & 5.948 & 4.91 & 4.036 & 4.662 & 4.602 \\
\hline$L=L^{*}$ & 9.463 & 7.642 & 9.075 & 7.182 & 8.934 & 7.303 \\
\hline \multicolumn{7}{|c|}{ (b) Cooperative policies } \\
\hline $\operatorname{var}(i)=\operatorname{var}\left(i^{*}\right)$ & & & 4.83 & 3.743 & 4.526 & 3.717 \\
\hline $\operatorname{var}(y)=\operatorname{var}\left(y^{*}\right)$ & & & 3.463 & 1.204 & 3.568 & 1.276 \\
\hline $\operatorname{var}(\pi)=\operatorname{var}\left(\pi^{*}\right)$ & & & 3.79 & 3.38 & 3.6 & 3.48 \\
\hline $\operatorname{var}(q)$ & & & 3.956 & 3.973 & 4.239 & 4.6 \\
\hline$L=L^{*}$ & & & 9.004 & 7.181 & 8.896 & 7.303 \\
\hline
\end{tabular}

Note: FW, inflation-forecast targeting with no response to exchange rate; FWQ, inflation-forecast targeting with response to exchange rate; FWS, inflation-forecast targeting with response to portfolio shocks. Both countries are using the same rule.

Table 6, part (a). For the more backward-looking Phillips curve $\left(\beta_{1}=0.9\right)$, reacting to the portfolio shock (column FWS) results in a better macroeconomic performance than does reacting to the exchange rate itself (column FWQ). The interest rate, inflation and the exchange rate become less variable; output is slightly more variable. There is an improvement in welfare. The value of the loss function falls from 9.075 to 8.934 . However, compared with the inflation-forecast rule (column FW), responding to portfolio shocks has only marginally stabilized inflation.

For the less backward-looking Phillips curve $\left(\beta_{1}=0.4\right)$, responding to the portfolio shock results in a higher loss (7.303) than responding to the exchange rate itself (7.182). Comparing the columns headed FWQ and FWS for non-cooperative policies in Table 6 it may be seen that the variances of output, inflation and the real exchange rate all increase. Responding to the portfolio shock when the economy has relatively little inertia makes it more variable. This shows that the results of Cecchetti et al. (2000) on the benefits of responding to such shocks depend on model formulation and parameter values, and may not be robust.

\section{Inflation TARgETING AND COOPERATION}

The analysis so far has assumed that the countries act independently of each other in choosing rules for their interest rates. That is, they act noncooperatively. In this section we turn our attention to the scope for cooperative policymaking to achieve better results. We stick with the situation of both countries' using inflation-forecast rules. Cooperative 
behaviour is modelled by having the policymakers in the two countries choose jointly the policy parameters that minimize their joint loss function. We first analyse the scope for cooperation when policymakers react explicitly neither to the exchange rate nor to the portfolio shock, and then we consider policy rules that include these reactions.

\subsection{Cooperative Rules that Respond Only to Domestic Variables}

In the setting analysed in Section 7.1, in which policy rules react only to domestic variables, cooperative behaviour by policymakers results in very similar optimal coefficients to the non-cooperative case. When the policy instrument reacts to deviations of the inflation forecast from the target, we find that the optimal policy parameter is equal to 2, in both the cooperative and the non-cooperative cases. Although the policy instrument reacts implicitly to the exchange rate, there are no gains from cooperation, independently of the degree of inflation persistence.

\subsection{Cooperative Rules that Respond to the Exchange Rate}

When policymakers in the two countries cooperate on the design of their inflation-forecast rules, including an explicit response to the exchange rate, the policy rules have the form FWQH and FWQF set out in equations (7) and (8) above. The optimal parameter values in the high-inflationpersistence case $\left(\beta_{1}=0.9\right)$ are $\gamma_{1}=\delta_{1}=1.7$ for expected inflation and $\gamma_{2}=\delta_{2}=0.3$ for the exchange rate. In the low-inflation-persistence case $\left(\beta_{1}=0.4\right)$ the corresponding figures are $\gamma_{1}=\delta_{1}=2.8$ and $\gamma_{2}=\delta_{2}=0.5$. These cooperative rules are very little different from the non-cooperative rules set out in Table 5. They differ only in that the response of the interest rate to the inflation forecast is slightly less strong, 1.7 as against 1.9 in the high-inflation-persistence case and 2.8 as against 2.9 in the lowinflation-persistence case. The responses to the exchange rate are not altered by cooperation. So a major benefit from cooperative policy here is not to be expected.

From the simulations summarized in Table 6 it can be seen that cooperation is beneficial only in the high-inflation-persistence case, and there the gains are modest. The loss falls from 9.075 to 9.004, a gain of less than 1 per cent. When countries cooperate, in this scenario, inflation becomes more variable and output less variable. The exchange rate also becomes less variable (4.0 as against 4.9). In the low-inflation-persistence case there are no differences between the non-cooperative and the cooperative outcomes worthy of note. 


\subsection{Cooperative Rules that Respond to Portfolio Shocks}

Should the European Central Bank and the Federal Reserve Bank of the USA cooperate in the presence of, let us say, an irrational love of dollars? That is the kind of question we explore in this section. That is, we analyse whether there are any gains from reacting cooperatively to a portfolio shock rather than non-cooperatively.

The policy rules once again take the form set out in equations (9) and (10). The optimal policy parameters when both countries react cooperatively to a portfolio shock are $\varphi_{1}=\varkappa_{1}=1.6$ for expected inflation and $\varphi_{2}=\varkappa_{2}=0.4$ for the portfolio shock in the high-inflation-persistence case $\left(\beta_{1}=0.9\right)$ and $\varphi_{1}=x_{1}=2.3$ for expected inflation and $\varphi_{2}=x_{2}=0.5$ for the portfolio shock in the low-inflation-persistence case $\left(\beta_{1}=0.4\right)$. Note that when policymakers respond cooperatively to the portfolio shock rather than to the exchange rate itself, their response to the inflation forecast is less aggressive (the coefficient is 1.5 rather than 1.7 for $\beta_{1}=0.9$; and 2.3 rather than 2.8 for $\beta_{1}=0.4$ ). The performance measures for the case where both countries react to the portfolio shock cooperatively are set out in Table 6. As in the previous case there are no benefits from cooperation in the case of low inflation persistence.

In the case of high inflation persistence, cooperation produces modest benefits relative to non-cooperation. The loss falls from 8.934 to 8.896 , a gain of less than 0.5 per cent.

\section{Sensitivity to Objective Function Weights}

In order to check the sensitivity of the results reported here to the weights used in the objective functions, a set of simulations was carried out in which the weight on output was reduced relative to that on inflation. The weights in the objective function, equation (21), were changed so that $\omega_{1}$, the weight on the variance of real output, became 0.2 rather than 1.0 as in the baseline simulations. The weight on inflation was maintained at 1.0. The consequence of this change for the results was very small. The conclusions of the baseline simulations are unaffected by this change. The principal effect is that the variance of inflation is somewhat reduced, and the variance of output somewhat increased, relative to the baseline. ${ }^{10}$ But the qualitative comparisons of different policy rules and between noncooperative and cooperative policies remain unchanged. The results appear to be robust with respect to reasonable variations in the objective function weights.

\footnotetext{
${ }^{10}$ For example, when both countries use the inflation-forecast rule non-cooperatively in the baseline case, the variance of inflation is 3.400 and of output is 3.898 . When the weight on output is cut to 0.2 the variances become 3.148 and 4.031 .
} 


\section{Conclusion}

In this paper we have simulated the effects of various policy rules in a world consisting of two open economies with floating exchange rates. The questions we wish to address concern: (1) the effects of inflation targeting on exchange rate volatility; (2) the possibilities for reducing exchange rate volatility and improving economic performance by countries' modifying their policy rules to include responses either to movements in exchange rates or to the portfolio shocks that affect exchange rates; (3) the benefits of countries' coordinating their interest rate policies.

Modelling the introduction of inflation targeting as a shift from the use of an optimized Taylor rule to the use of an inflation-forecast rule for interest rates, we find that exchange rate volatility rises substantially (by roughly one-third) and economic performance generally worsens. Inflation becomes less variable, but at the price of greater variability of output and interest rates.

In the context of countries using optimized Taylor rules for policy, introducing a response of interest rates to exchange rate movements brings about a small improvement in overall performance, made up of lower volatility of interest rates offset partly by higher volatility of output and inflation. The volatility of the exchange rate is significantly reduced. Of all the scenarios we simulated, this one, with countries using optimized Taylor rules augmented by a response to exchange rate movements, despite the absence of coordination of policy between countries, yields the best overall performance when inflation is not too persistent, and close to the best when inflation is more persistent.

In the context of countries using inflation-forecast rules, the introduction of a response of interest rates to the exchange rate brings significant improvements in performance, whether policy is coordinated or not. These gains result from lower variance of the policy instrument and of output. The exchange rate also becomes much less variable.

Responding to the portfolio shock rather than to the exchange rate itself may have modest benefits, but these depend on a key parameter, the degree of inflation persistence. If inflation is highly persistent, then responding to portfolio shocks proves beneficial. If inflation is not very persistent, then responding to the portfolio shock may be less good than responding to the exchange rate itself.

The simulations suggest that modifying policy rules to include a response to portfolio shocks can bring about significant reductions in the volatility of interest rates and exchange rates, and an improvement in overall performance. In our simulations, the improvements in overall performance typically consist of lower variances of output and interest rates, partly offset by slightly higher inflation variance. Thus we have not shown that an improvement in every dimension of performance can be 
achieved. But it seems likely that a different selection of policy rules would be able to achieve this. Our policy rules have been chosen with reference to an objective function that weights output variance and inflation variance equally, and gives weight to the variance of interest rate changes.

The simulations suggest that further modest gains can be obtained by international coordination of interest rate rules, when these contain some response either to exchange rates per se or to the portfolio shocks that affect them.

In the present paper the analysis has necessarily been limited in its scope, and suggests many questions for further exploration. The model has imposed numerous assumptions. We have tried to choose widely acceptable ones, but inevitably some are more contentious, and the results may be sensitive to some of these. Our analysis reveals the sensitivity of the results to the assumed degree of inflation persistence. The question of the lag structure is particularly sensitive and worthy of further enquiry, as is the related issue of the transmission mechanism of interest rates.

We have restricted the paper to consideration of a small number of policy rules. While these have the virtue of simplicity and descriptive realism, they raise the problem of operating in a second best world. There are many possible alternative rules that might be compared. It would be interesting to explore the benchmark provided by the optimal state- or shock-contingent policy rules. Our results are based on a particular choice of objective function, and while this attempts to reproduce a consensus view of policy objectives, it would be useful to explore alternatives.

Notwithstanding these cautionary notes, we argue that the paper shows that augmenting interest rate policy rules by responses to the portfolio shocks that affect exchange rates may, depending on parameter values, have beneficial effects. This reinforces the case for offsetting 'irrational love of dollars' and other non-fundamental movements in exchange rates. It appears that this introduces a degree of surrogate international coordination because, while there are additional gains for explicit international policy coordination, these are very small.

\section{REFERENCES}

Ball, L. (1997). 'Efficient Rules for Monetary Policy', International Finance, Vol. 2, No. 1, pp. 63-83.

Ball, L. (1999). 'Policy Rules for Open Economies', in J. Taylor (ed.), Monetary Policy Rules, Chicago, IL, University of Chicago Press.

Batini, N. and Haldane, A. (1999). 'Forward-looking Rules for Monetary Policy', in J. Taylor (ed.), Monetary Policy Rules, Chicago, IL, University of Chicago Press.

Batini, N. and Nelson, E. (2000). 'Optimal Horizons for Inflation Targeting', Bank of England Working Paper 119. 
Bernanke, B., Laubach, T., Mishkin, F. and Posen, A. (1999). Inflation Targeting: Lessons from the International Experience, Princeton, NJ, Princeton University Press.

Black, R., Macklem, T. and Rose, D. (1997). 'On Policy Rules for Price Stability', in Price Stability, Inflation Targets and Monetary Policy, Ottawa, Bank of Canada; http://www.bankofcanada.ca/en/conf_idx.htm.

Blanchard, O. J. and Kahn, C. (1980). 'The Solution of Linear Difference Models under Rational Expectations', Econometrica, Vol. 48, No. 5, pp. 1305-1311.

Brayton, F., Roberts, J. and Williams, J. (1999). 'What's Happened to the Phillips Curve?', FEDS Working Paper 1999-49, Federal Reserve Board, Washington, DC.

Buiter, W. H. and Marston, R. C. (eds) (1984). International Economic Policy Coordination, Cambridge, Cambridge University Press.

Canzoneri, M. B. and Henderson, D. W. (1991). Monetary Policy in Interdependent Economies, Cambridge, MA, MIT Press.

Cecchetti, S., Genberg, H., Lipsky, J. and Wadhwani, S. (2000). Asset Prices and Central Bank Policy, International Center for Monetary and Banking Studies, Centre for Economic Policy Research.

Chadha, B., Masson, P. and Meredith, G. (1992). 'Models of Inflation and the Costs of Desinflation', IMF Staff Papers, Vol. 39, pp. 395-431.

Clarida, R., Gertler, M. and Gali, J. (1998). 'Monetary Policy Rules in Practice: Some International Evidence', European Economic Review, Vol. 42, pp. 1033 1067.

Estrella, A. and Fuhrer, J. C. (1998). 'Dynamic Inconsistencies: Counterfactual Implications of a Class of Rational Expectations Models', Federal Reserve Bank of Boston, July.

Fair, R. (1993). 'Testing the Rational Expectations Hypothesis in Macroeconometric Models', Oxford Economic Papers, Vol. 45, pp. 169-190.

Freedman, C. (2000). 'The Framework for the Conduct of Monetary Policy in Canada: Some Recent Developments', Presentation to the Ottawa Economics Association.

Fuhrer, J. C. (1997). 'The (Un)Importance of Forward-looking Behaviour in Price Specifications', Journal of Money, Credit, and Banking, August, pp. 338-350.

Fuhrer, J. C. and Moore, G. R. (1995). 'Inflation Persistence', Quarterly Journal of Economics, Vol. 110, pp. 127-159.

Hamilton, J. D. (1994). Time Series Analysis, Princeton, NJ, Princeton University Press.

Jensen, H. (2000). 'Optimal Monetary Policy Cooperation through Stateindependent Contracts with Targets', European Economic Review, Vol. 44, March, pp. 517-539.

McCallum, B. T. (1997). 'The Alleged Instability of Nominal Income Targeting', NBER Working Paper 6291.

McCallum, B. T. and Nelson, E. (1999a). 'Performance of Operational Policy Rules in an Estimated Semi-classical Structural Model', in J. Taylor (ed.), Monetary Policy Rules, Chicago, IL, University of Chicago Press.

McCallum, B. T. and Nelson, E. (1999b). 'An Optimising IS-LM Specification for Monetary Policy and Business Cycle Analysis', Journal of Money, Credit and Banking, Vol. 31, pp. 296-316.

Mishkin, F. (1999). 'Comment', in J. Taylor (ed.), Monetary Policy Rules, Chicago, IL, University of Chicago Press.

Obstfeld, M. and Rogoff, K. (2000). 'Do We Really Need a New International Monetary Compact?', NBER Working Paper 7864, August. 
Persson, T. and Tabellini, G. (1995). 'Double-edged Incentives: Institutions and Policy Coordination', in G. Grossman and K. Rogoff (eds), Handbook of International Economics, Vol. 3, Amsterdam, Elsevier.

Persson, T. and Tabellini, G. (2000). Political Economics: Explaining Economic Policy, Cambridge, MA, MIT Press.

Rogoff, K. (1985). 'Can International Monetary Policy Coordination be Counterproductive?', Journal of International Economics, Vol. 18, May, pp. 199-217.

Rotemberg, J. and Woodford, M. (1999). 'Interest Rate Rules in an Estimated Sticky-price Model', in J. Taylor (ed.), Monetary Policy Rules, Chicago, IL, University of Chicago Press.

Rudebusch, G. D. (2000). 'Assessing Nominal Income Rules for Monetary Policy with Model and Data Uncertainty', Federal Reserve Bank of San Francisco, October.

Rudebusch, G. and Svensson, L. (1999). 'Policy Rules for Inflation Targeting', in J. Taylor (ed.), Monetary Policy Rules, Chicago, IL, University of Chicago Press.

Ryan, C. and Thompson, C. (2000). 'Inflation Targeting and Exchange Rate Fluctuations in Australia', Reserve Bank of Australia Research Discussion Paper 2000-6.

Smets, F. (1997). 'Financial Asset Prices and Monetary Policy: Theory and Evidence', CEPR Working Paper 1751.

Söderlind, P. (1999). 'Solution and Estimation of RE Macromodels with Optimal Policy', European Economic Review, Vol. 43, pp. 813-823.

Sutherland, A. (2000). 'Inflation Targeting in a Small Open Economy', Unpublished paper, available at http://www.st-and.ac.uk/ ajs10.

Svensson, L. E. O. (1997). 'Inflation Forecast Targeting: Implementing and Monitoring Inflation Targets', European Economic Review, Vol. 41, No. 6, pp. 1111-1146.

Svensson, L. E. O. (1999). 'Inflation Targeting: Some Extensions', Scandinavian Journal of Economics, Vol. 101, pp. 337-361.

Svensson, L. E. O. (2000). 'Open-economy Inflation Targeting', Journal of International Economics, Vol. 50, pp. 155-184.

Taylor, J. B. (1993). 'Discretion vs. Policy Rules in Practice', Carnegie-Rochester Conference Series on Public Policy, Vol. 39, pp. 195-214.

Taylor, J. B. (ed.) (1999). Monetary Policy Rules, Chicago, IL, University of Chicago Press.

Walsh, C. E. (1998). Monetary Theory and Policy, Cambridge, MA, MIT Press.

Weerapana, A. (2000). 'The Performance of Simple Monetary Policy Rules in a Large Open Economy', Wellesley College Working Paper 2000-05.

Woodford, M. (1999). 'Optimal Monetary Policy Inertia', NBER Working Paper 7261. 